\title{
Overcoming bumps to build little pumps
}

\author{
Ming-Sing Si, MD
}

From the Section of Pediatric Cardiovascular Surgery, Department of Cardiac Surgery, University of Michigan, Ann Arbor, Mich.

Disclosures: Author has nothing to disclose with regard to commercial support.

Received for publication April 30, 2018; revisions received April 30, 2018; accepted for publication May 2, 2018; available ahead of print June 19, 2018.

Address for reprints: Ming-Sing Si, MD, 11-735 C.S. Mott Children's Hospital SPC 4204, 1540 E Hospital Dr, Ann Arbor, MI 48109-4204 (E-mail: mingsing@umich.edu).

J Thorac Cardiovasc Surg 2018;156:1652-3

$0022-5223 / \$ 36.00$

Copyright (C) 2018 by The American Association for Thoracic Surgery

https://doi.org/10.1016/j.jtcvs.2018.05.009

Although heart transplantation is the gold standard treatment for end-stage heart failure, children have the highest waitlist mortality rate compared with adults and other solid organ transplantations. ${ }^{1}$ The mortality is especially high for neonates and infants who weigh less than $5 \mathrm{~kg}$. Larger children and adults can be successfully bridged to heart transplantation with a suite of mechanical circulatory support (MCS) options, with continuous-flow devices incorporating magnetically-levitated rotors as being the current state of the art.

However, MCS for infants and neonates represents a critical area of much needed development. Venoarterial extracorporeal life support as a bridge to heart transplantation is associated with poor outcomes. ${ }^{2}$ The Berlin Excor Pediatric (Berlin Heart GmbH, Berlin, Germany) extracorporeal ventricular assist device in this small-sized patient population is also associated with decreased survival. ${ }^{3}$ These dismal results confirm that heart failure in neonates and infants carries a particularly grave prognosis and that better MCS devices are needed.

Because of the relatively small financial incentive for industry to develop advanced MCS devices for children, the National Institutes of Health has supported much of the initial development of these devices. ${ }^{4}$ One of these devices is the PediaFlow (LaunchPoint Technologies Inc, Goleta, Calif) infant ventricular assist device and is described in detail in this issue of The Journal of Thoracic and Cardiovascular Surgery by Olia and colleagues from the University of Pittsburgh. ${ }^{5}$ This report describes the development and preclinical performance of their PediaFlow device. The most current iteration of the device, the PF4 (LaunchPoint Technologies Inc), can be seen as a miniature counterpart to the most current adult device that has magnetic bearings. These investigators also developed and described the inflow and outflow components for the device, with specific attention to decrease thrombosis. The operating range of the PF4 device is 0.5 to $1.5 \mathrm{~L} / \mathrm{min}$-certainly within the $\mathrm{CO}$ requirements for most neonates and infants with single or biventricular circulation. In vitro testing showed hemolysis rates comparable with that of the extracorporeal,

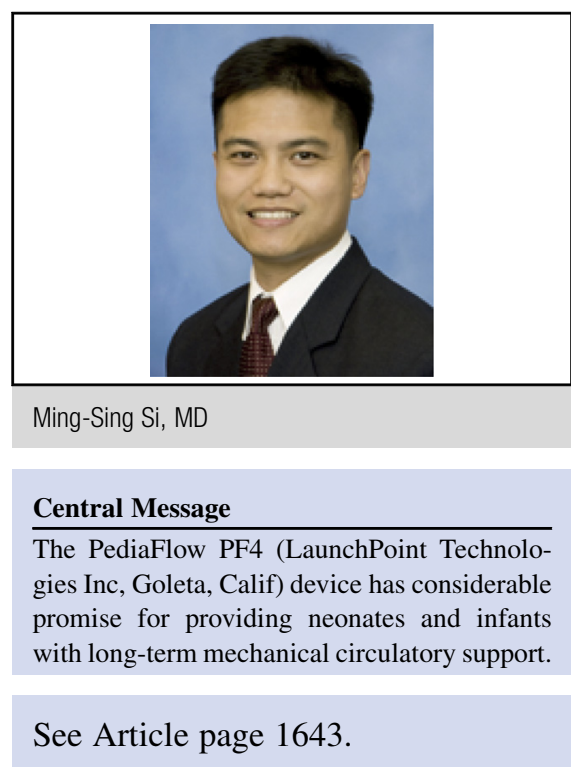

magnetically-levitated Pedimag device (Thoratec Corp, Pleasanton, Calif). Sixty-day in vivo testing of the PF4 device in lambs revealed favorable biocompatibility and hemolysis, however there were only 2 animal implantations that were carried to this longer time course. Nonetheless, these results indicate significant promise for the Pediaflow PF4 device.

The Infant Jarvik 2015 (Jarvik Heart Inc, New York, NY) is another infant ventricular assist device whose development was supported by the National Institutes of Health. This device was supposed to be evaluated in a clinical trial, however because of poor enrollment it has now been placed on hold. A detailed assessment of the Jarvik 2015 was given recently in The Journal of Thoracic and Cardiovascular Surgery. ${ }^{6}$ It appears that the Jarvik 2015 might be more suited for larger infants and has comparable in vitro and in vivo hemocompatibility. Although a direct comparison of the Jarvik 2015 and PediaFlow PF4 devices is difficult to make without conducting a head-to-head trial, the existing data indicate that both might have similar performance. It would be interesting to see if the hemolysis and thrombotic events would be lower in the PF4 device because of its magnetic bearings and cannula design.

The PediaFlow PF4 and Jarvik 2015 represent decades of innovation and commitment of surgeons, engineers, and others to the development of a state of the art miniature MCS device. Numerous bumps in the road have been overcome to yield the current versions of these devices. The field anxiously awaits successful human trials of these devices so 
that it can then be used to save the smallest and most vulnerable population affected by end-stage heart failure.

\section{References}

1. Almond CS, Thiagarajan RR, Piercey GE, Gauvreau K, Blume ED, Bastardi HJ, et al. Waiting list mortality among children listed for heart transplantation in the United States. Circulation. 2009;119:717-27.

2. Dipchand AI, Mahle WT, Tresler M, Naftel DC, Almond C, Kirklin JK, et al. Extracorporeal membrane oxygenation as a bridge to pediatric heart transplantation: effect on post-listing and post-transplantation outcomes. Circ Heart Fail. 2015;8:960-9.
3. Almond CS, Morales DL, Blackstone EH, Turrentine MW, Imamura M Massicotte MP, et al. Berlin Heart EXCOR pediatric ventricular assist device for bridge to heart transplantation in US children. Circulation. 2013;127:1702-11.

4. Baldwin JT, Borovetz HS, Duncan BW, Gartner MJ, Jarvik RK, Weiss WJ. The National Heart, Lung, and Blood Institute Pediatric Circulatory Support Program: a summary of the 5-year experience. Circulation. 2011;123:1233-40.

5. Olia SE, Wearden PD, Maul TM, Shankarraman V, Kocyildirim E, Snyder ST, et al. Preclinical performance of a pediatric mechanical circulatory support device: The PediaFlow ventricular assist device. J Thorac Cardiovasc Surg. 2018;156: 1643-51.

6. Adachi I, Burki S, Horne D, Costas GG, Spangler T, Jarvik R, et al. The miniaturized pediatric continuous-flow device: preclinical assessment in the chronic sheep model. J Thorac Cardiovasc Surg. 2017;154:291-300. 